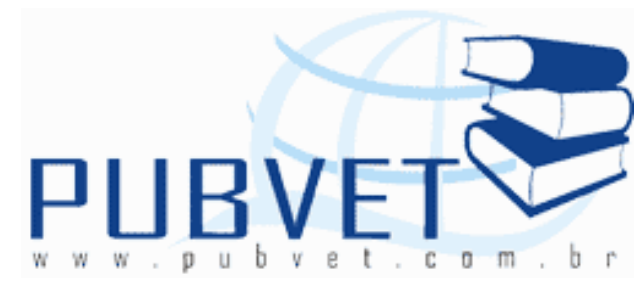

PUBVET, Publicações em Medicina Veterinária e Zootecnia.

\title{
Pesquisa de Staphylococcus coagulase positiva em queijo Minas Frescal artesanal
}

Renata Marques Ferreira ${ }^{1}$; Janise De Castro Moraes Spini ${ }^{1}$; Leonardo Gomes Carrazza $^{2}$; Driele Schneidereit Sant'ana²; Millene Torres de Oliveira²; Luana Ribeiro Alves ${ }^{2}$; Thaís Gomes Carrazza ${ }^{3}$

${ }^{1}$ Médica Veterinária.

${ }^{2}$ Mestrando do Programa de Pós-Graduação em Ciências Veterinárias da Universidade Federal de Uberlândia - UFU.

${ }^{3}$ Graduanda do curso de Medicina Veterinária da Universidade Federal de Uberlândia - UFU.

\section{Resumo}

A presente pesquisa teve como objetivo avaliar a qualidade microbiológica do queijo Minas Frescal artesanal, através da análise de Staphylococcus coagulase positiva. Foram analisadas 20 amostras, comercializadas em feiras livres da cidade de Uberlândia, Minas Gerais. Os resultados obtidos mostraram que 18 (90\%) estavam com contagem acima do padrão estabelecido para Staphylococcus coagulase positiva. A partir destes resultados pode-se concluir que a qualidade microbiológica apresentou-se insatisfatória, representando um risco à saúde do consumidor.

Palavras-chave: Contagem bacteriana, contaminação, leite cru 


\title{
Search by coagulase positive Staphylococcus in artisan Minas cheese
}

\begin{abstract}
This study aimed to evaluate the microbiological quality of artisan Minas cheese, through analysis of coagulase positive Staphylococcus. Were analyzed 20 samples, sold in street markets of the city of Uberlandia, Minas Gerais. The results showed that $18(90 \%)$ had counts above the established standard for coagulase positive Staphylococcus. From these results we can conclude that the microbiological quality was unsatisfactory, representing a risk to consumer health.
\end{abstract}

Keywords: Bacterial count, contamination, raw milk

\section{INTRODUÇÃO}

Entende-se por queijo Minas Frescal, o queijo fresco obtido por coagulação enzimática do leite com coalho e/ou outras enzimas coagulantes apropriadas, complementada ou não pela ação de bactérias lácticas específicas (BARROS et al., 2004). Este tipo de queijo é caracterizado pelo alto teor de umidade, massa branca, consistência mole, textura fechada com algumas olhaduras irregulares, sabor suave a levemente ácido. Tem elevado valor nutritivo com grande concentração de proteínas, sais minerais e vitaminas além de ser rico em fósforo e cálcio (TRONCO, 1996).

Por ter um preço acessível e ser de fácil fabricação, é um produto amplamente consumido em diversas regiões do Brasil. É também conhecido como queijo branco, queijo Minas ou Frescal (SABIONI et al., 1988).

A pecuária de leite, associada à fabricação artesanal de queijos com venda direta ao consumidor em feiras livres é comum em diversas regiões do país. Entretanto, na maioria das vezes estes produtos são elaborados a partir de leite sem qualquer tratamento térmico, com condições higiênico-sanitárias duvidosas, o que leva à produção de um derivado de qualidade inferior, senão 
potencialmente capaz de comprometer a saúde de seus consumidores (SILVA, 1998).

Os possíveis defeitos encontrados nestes produtos estão relacionados diretamente com a qualidade físico-química da matéria prima utilizada, bem como a má higiene do local onde está sendo fabricado o queijo, a manipulação inadequada e a permanência do produto, desde a produção até sua comercialização, em temperaturas que suportam o desenvolvimento de microrganismos prejudiciais à saúde do homem, sendo, portanto um problema de Saúde Pública (BARROS et al., 2004).

Dentre os microrganismos mais importantes encontrados em leite e derivados, como os queijos estão os Staphylococcus aureus, que podem ser transmitidos tanto pelo leite contaminado por vacas que apresentem mastite estafilocóccica como pela manipulação e contaminação através do ser humano (GERMANO; GERMANO, 2001).

O Staphylococcus aureus é freqüentemente pesquisado em alimentos, sendo o queijo, um dos principais veículos causadores de toxinfecção alimentar, pois sua presença está associada a práticas de higiene e manipulação inadequadas (LOGUERCI; ALEIXO, 2001).

Por muitos anos Staphylococcus aureus foi considerado a única espécie do gênero Staphylococcus capaz de produzir enterotoxinas, bem como de produzir coagulase. Posteriormente outras espécies relacionadas a surtos de intoxicação alimentar foram identificadas, em função deste fator houve uma mudança na legislação brasileira que passou a estabelecer a pesquisa e enumeração de estafilococos coagulase positiva ao invés da enumeração Staphylococcus aureus (SILVA; GANDRA, 2004).

De acordo com a resolução $-\operatorname{RDC} \mathrm{n}^{\circ}$. 12, de 2 de janeiro de 2001 (ANVISA), o padrão microbiológico para Staphylococcus coagulase positiva é de no máximo $5 \times 10^{2} \mathrm{UFC} / \mathrm{g}$.

A pesquisa teve por objetivo avaliar a qualidade microbiológica do queijo Minas Frescal artesanal, comercializado na cidade de Uberlândia - Minas 
Gerais, através da determinação da presença de Staphylococcus coagulase positiva.

\section{MATERIAL E MÉTODOS}

Foram analisadas 20 amostras de queijo Minas Frescal artesanal de 4 diferentes pontos de vendas localizados em feiras livre da cidade de Uberlândia - MG , no período de setembro e outubro de 2006. Os pontos de coleta foram denominados A, B, C e D. As amostras foram acondicionadas em sacos plásticos estéreis e identificados, logo após a coleta foram transportadas em caixas isotérmicas com gelo até o Laboratório de Controle de Qualidade e Segurança Alimentar, da Faculdade de Medicina Veterinária da Universidade Federal de Uberlândia (LCQSA/FAMEV/UFU).

Após chegarem ao laboratório, foram pesadas assepticamente 10 gramas de cada amostra e adicionado $90 \mathrm{~mL}$ de solução salina peptonada estéril a $0,1 \%$. As diluições seriadas de $10^{-1}$ a $10^{-3}$ foram utilizadas para as etapas seguintes.

A partir das diluições preparadas $\left(10^{-1}, 10^{-2}, 10^{-3}\right)$ foi inoculado $0,1 \mathrm{~mL}$ de cada diluição em superfície de placas contendo Ágar BP, (previamente preparadas e secadas) espalhou-se o inóculo com auxílio de uma alça estéril. Feito isso, as placas foram incubadas invertidas a $35^{\circ} \mathrm{C}$ por $48 \mathrm{~h}$.

Após este período contaram-se as colônias típicas (máx. 1,5 mm de diâmetro, lisas, convexas, com bordas perfeitas, massa de células esbranquiçadas nas bordas, rodeadas por um halo transparente estendendo para além da zona opaca) e colônias atípicas (colônias cinzentas, sem um ou ambos os halos típicos de Staphylococcus). O resultado foi obtido pelo $\mathrm{n}^{\circ} \mathrm{de}$ colônias (UFC/g) contadas e diluição inoculada. Para confirmação de resultados foi feita coloração de Gram.

Foram coradas lâminas de cada placa onde houve crescimento de colônias. As colônias foram espalhadas nas lâminas, fazendo esfregaço, acrescentando uma gota de água para uma melhor distribuição. A coloração 
obedeceu a seguinte ordem: Cristal violeta; água destilada; iodo; segunda lavagem com água destilada; álcool - acetona para 'descorar'; fucsina; lavagem em água corrente; secagem das lâminas em estufa por 5 minutos; visualização ao microscópio óptico.

A partir de cada placa selecionada foram colhidas 5 colônias típicas e atípicas e semeadas em tubos estéreis contendo $0,2 \mathrm{~mL}$ de caldo cérebro coração ( $B H I$ ).Os tubos foram identificados como A, B, C, D, E, sendo que cada letra corresponde a uma colônia. Após a inoculação os tubos foram incubados a $37^{\circ} \mathrm{C}$ por $24 \mathrm{~h}$. Após serem incubados, adicionou-se $0,2 \mathrm{~mL}$ de plasma oxalato de coelho a cada tubo contendo o BHI, incubando-se novamente por $24 \mathrm{~h}$ em banho-maria, a uma temperatura de $370 \mathrm{C}$. Foram considerados positivos os tubos que apresentaram coágulo evidente.

\section{RESULTADOS E DISCUSSÃO}

A Tabela 1 mostra o resultado da análise microbiológica das amostras de queijo minas frescal artesanal, sendo representados os valores mínimos e máximos (UFC/g) de Staphylococcus coagulase positiva, e a conformidade dos resultados com a resolução - RDC no. 12, de 2 de janeiro de 2001 (ANVISA).

Tabela 1: Valores mínimos e máximos de UFC/g, dos queijos minas frescal artesanal, coletados em diferentes pontos de venda. Uberlândia-MG. Setembro e Outubro, 2006.

\begin{tabular}{ccc}
\hline PONTOS DE COLETA & NO DE AMOSTRAS & $\begin{array}{c}\text { VALORES MÍNIMOS E MÁXIMOS } \\
(\text { UFC/g) }\end{array}$ \\
\hline A & 6 & $2,4 \times 10^{3}-8 \times 10^{4}$ \\
B & 5 & $1,7 \times 10^{4}-2,8 \times 10^{4}$ \\
C & 5 & $1,1 \times 10^{4}-2,6 \times 10^{5}$ \\
D & 4 & $2,4 \times 10^{4}-2,1 \times 10^{5}$ \\
Total & 20 & $2,4 \times 10^{3}-2,6 \times 10^{5}$ \\
*Padrão & - & $5 \times 10^{2}$ \\
\hline
\end{tabular}


Analisando-se os resultados obtidos, na Tabela 2, de acordo com os padrões estabelecidos, 18 (90\%) amostras apresentam contagens acima do padrão estabelecido para Staphylococcus coagulase positiva.

Tabela 2: Resultado da análise de 20 amostras de queijo minas frescal artesanal, em relação aos padrões estabelecidos para Staphylococcus coagulase positiva UFC/g. Uberlândia-MG. Setembro e Outubro, 2006.

STAPHYLOCOCCUS COAGULASE

DETERMINAÇÕES POSITIVA (UFC/g)

NO AMOSTRAS $\%$

DENTRO DOS PADRÕES

FORA DOS PADRÕES

TOTAL
2

18

20
10

90

100

Das 20 amostras analisadas, 9 ( 45\%) apresentaram coágulo evidente na prova da coagulase, indicando a presença de Staphylococcus coagulase positiva.

Os pontos de coleta A e B não mantinham o produto sob refrigeração adequada mantendo-os dentro de caixas de isopor sem gelo. Nos pontos C e $D$, os queijos ficavam expostos sobre o balcão durante a manhã toda. Isto pode ter contribuído para as altas contagens de Staphylococcus coagulase positiva.

Os valores encontrados nesta pesquisa para Staphylococcus coagulase positiva são superiores aos valores que ALMEIDA FILHO et al. (2000) encontraram, pois de 80 amostras de queijo minas frescal analisadas, 40 (50\%) apresentavam contagem acima de $10^{3} \mathrm{UFC} / \mathrm{g}$. Já no trabalho realizado por Loguercio e Aleixo (2001), também com queijo minas frescal produzido artesanalmente, 29 amostras $(96,67)$ apresentaram contagens superiores ao padrão legal aceitável para Staphylococcus aureus. 
SILVA (1998), em trabalho semelhante, verificou que em 60 amostras de queijo minas frescal examinadas na Cidade do Rio de Janeiro, RJ, 38,4\% das amostras apresentaram contagem de Staphylococcus aureus superiores a $10^{3}$ UFC/g, enquanto Mandil et al. (1993) constataram que $67 \%$ das amostras do mesmo produto apresentaram contagens do mesmo microrganismo variando de $10^{1}$ a $10^{6} \mathrm{UFC} / \mathrm{g}$.

De acordo com Salotti et al. (2006) de 30 amostras de queijo minas frescal artesanal analisadas na cidade de Jaboticabal, SP, 6 (20\%) apresentaram contagens acima do padrão permitido para Staphylococcus coagulase positiva, variando entre $5 \times 10^{3} \mathrm{UFC} / \mathrm{g}$ a $>5 \times 10^{4} \mathrm{UFC} / \mathrm{g}$.

$\mathrm{Na}$ análise de 20 amostras de queijos coletados em Blumenau-SC realizada por Reibinitz et al. (1998), verificou-se a presença de Staphylococcus coagulase positiva em $95 \%$ das amostras.

A presença de Staphylococcus nas amostras representa falta de higiene, principalmente dos manipuladores de alimentos. Estes albergam principalmente o Staphylococcus aureus que é de grande interesse para a Saúde Pública, por estar relacionado a surtos de intoxicação alimentar. A utilização de leites pasteurizados, provenientes de vacas sadias também é de extrema relevância, pois a mastite estafilocócica é uma das causas da presença de Staphylococcus em alimentos derivados de leite.

Em pesquisa realizada por Lamaita et al. (2005), em 80 amostras de leite cru coletadas em propriedades produtoras de leite em Belo Horizonte, no período de outubro a dezembro de 2002, foram detectados em $100 \%$ das amostras do leite refrigerado contagens que variaram de $1,0 \times 10^{5}$ a $2,5 \times 10^{7}$ UFC/g de Staphylococcus sp. Isso pode ser explicado pela diversificação de sistemas de produção e de manejos utilizados pelos produtores, o que leva à maior ou menor contaminação do leite por Staphylococcus sp. devido à mastite ou por contaminação de retireiros portadores assintomáticos. 
FERREIRA, R.M. et al. Pesquisa de Staphylococcus coagulase positiva em queijo Minas Frescal artesanal. PUBVET, Londrina, V. 5, N. 5, Ed. 152, Art. 1021, 2011.

\section{CONCLUSÃO}

A partir dos resultados obtidos com este trabalho, pode-se concluir que a contaminação microbiológica do queijo minas frescal artesanal por Staphylococcus coagulase positiva é alta, e representa um perigo sério para a saúde do consumidor levando também a prejuízos econômicos. Portanto há a necessidade de implantação de programas de boas práticas de fabricação em todos os níveis da produção queijeira e análise de seus pontos críticos, além de um adequado sistema de vigilância nos pontos de venda.

\section{REFERÊNCIAS BIBLIOGRÁFICAS}

ANVISA, Resolução-RDC no. 12, de 2 de janeiro de 2001, disponível em http://www.anvisa.gov.br/legis/resol. Acesso em: 12, set. 2006.

BARROS, P.C.O.G.; NOGUEIRA, L.C.; RODRIGUEZ, E.M.; CHIAPPINI, C.C. Avaliação da qualidade microbiológica do queijo minas frescal comercializado no município do Rio de Janeiro, RJ. Revista Higiene Alimentar, São Paulo, v.18, n.122, p.32-37, Julho, 2004.

GERMANO, P.M.L.; GERMANO, M.I.S. Higiene na ordenha. Higiene e Vigilância sanitária dos alimentos, São Paulo: Livraria Varela, parte 4, p.80-89, 2001,655p.

LAMAITA, H.C.; CERQUEIRA, M.M.P.; CARMO,L.S.; SANTOS, D.A. ; PENNA, C.F.A. M.; SOUZA, M.R. Contagem de Staphylococcus sp. e deteç̧ão de enterotoxinas estafilocócicas e toxina da síndrome do choque tóxico em amostras de leite cru refrigerado. Arquivo Brasileiro de Medicina Veterinária e Zootecnia. vol.57, no.5, Belo Horizonte, Outubro 2005.

LOGUERCIO, A.P.; ALEIXO, J.A.G. Microbiologia do queijo tipo minas frescal produzido artesanalmente. Ciência Rural. Santa Maria, v.31, n.6, 2001. Disponível em: http: //www.scielo.br/scielo.php/Ing em.Acesso em: 18 de set. 2005.

MANDIL, A.; MORAIS, V.A.D.; PEREIRA, M.L.; FAGUNDES, J.M.S.; CARMO, L.S.; CORREIA, M.G.; CASTRO, E.P.; GOMES, M.J.V.M. Avaliação da qualidade microbiológica de queijos comercializados em Belo Horizonte, MG, no período de 1984 a 1991. In: Encontro nacional de analistas de alimentos, 8., 1993, Porto Alegre. Anais. Porto Alegre, 1993.

REIBNITZ, M.G.R.; TAVARES, L.B.B.; GARCÍA, J.A. Presencia de coliformes fecales, Escherichia coli y Staphylococcus aureus coagulasa y DNAsa positivos em queso. Revista Argentina de microbiologia, Buenos Aires, v.30, n.1, p.8-12, 1998.

SABIONI, G.J.; HIROOKA, Y. E.; SOUZA, R.L.M. Intoxicação alimentar por queijo minas contaminado com Staphylococcus aureus . Revista da Saúde Pública, São Paulo, v.22, n.5, outubro 1998. 
FERREIRA, R.M. et al. Pesquisa de Staphylococcus coagulase positiva em queijo Minas Frescal artesanal. PUBVET, Londrina, V. 5, N. 5, Ed. 152, Art. 1021, 2011.

SALOTTI, B.M.; CARVALHO, C.F.B.; AMARAL, A.;MARTINS,A.M.C.;CORTEZ,A.L. Qualidade microbiológica do queijo minas frescal comercializado no Município de Jaboticabal, SP, no período de julho a dezembro de 2002. Arq. Inst. Biol., São Paulo, v.73, n.2, p.171-175, abr./jun., 2006.

SILVA, C.A.M. Avaliação da qualidade microbiológica de queijo minas frescal consumido na cidade do Rio de Janeiro. In: Congreso brasileiro de ciências e tecnologia de alimentos, 17, 1998, Fortaleza. Anais. Fortaleza, 1998, p.134.

SILVA, W.P.; GANDRA, E.A. Estafilococos coagulase positiva: patógenos de importância em alimentos. Revista Higiene Alimentar, São Paulo, v.18, n.122, p.32-37, Julho 2004.

TRONCO, M.V. Aproveitamento do leite: Elaboração de seus derivados na propriedade rural, 1.ed, Guaíba: Agropecuária, 1996. p. 196. 